\section{Kirsty Dawe}

is Co-Founder and Marketing Strategy Director for Really B2B, a results-focused business-tobusiness marketing agency working for clients such as BBC, Orange Business Services, Compass Group, Santander and HSBC. She is also Marketing Director for the Market Makers group. Prior to this, she headed up marketing for the IP-tracking software firm Lead Forensics.

Keywords: business-to-business marketing, email marketing, content strategy

\section{Sales cycle nurturing}

\section{Lengthy buying cycle}

\section{Thought-leadership content}

\section{Kirsty Dawe}

Really B2B, 1000 Lakeside, North Harbour, Western Road, Portsmouth PO6 3EN, UK

Tel: +44 (0)2392315607

E-mail: kirsty@reallyb2b.com

\section{Case Study}

\section{Miele Professional}

\section{Kirsty Dawe}

Received (in revised form): 1st April 2015

\begin{abstract}
Miele Professional provides laundry and cleaning equipment and processes for which it identified the care home sector and hotel industry as prime prospects. Through the adoption of a content-driven email-led integrated marketing strategy, it has been able to achieve growth in sales through better engagement with prospects along the buying cycle. Journal of Direct, Data and Digital Marketing Practice (2015) 16, 278-281. doi:10.1057/dddmp.2015.25
\end{abstract}

\section{Background}

Miele Professional is one of the world's leading manufacturers of highquality appliances for professional use. For over 100 years, it has been leading the way with innovative laundry/cleaning equipment and processes. With an extensive range of highly engineered machines, Miele Professional is one of the best-known names in its industry. In order to grow the business further, it had very clear objectives that it wanted to achieve. The company wished to engage with both customers and prospects on a regular basis in order to nurture them throughout an ongoing sales cycle. It also aimed to achieve uplift in overall lead volume and generate this result in a measurable way with proven return on investment (ROI).

In addition to this, it was vitally important that all new marketing activity was incorporated effectively into Miele Professional's existing lead generation and marketing strategy. As the target audience typically only updated its laundry equipment every few years, it was important for Miele Professional to keep the brand at the forefront of prospects' minds and nurture them between buying cycles.

\section{Strategy overview}

In order to meet all of Miele Professional's objectives, it was necessary to employ an integrated multi-channel campaign. By approaching prospects via multiple channels with targeted messaging, it would be possible to increase the existing number of leads. However, in order to nurture the leads through the sales cycle, we would need a new approach in addition to the typical strategy of email and telephone 'touches'. It was decided that thought-leadership content would not only improve the lead generation and nurturing process, but would also help prospects build brand affinity and understand Miele Professional's expertise in the industry. 
Researching personas

\section{Analyzing patterns in pain points}

\section{Understanding the target audience}

\section{Care home challenges}

Hotel challenges

\author{
Content-driven \\ strategy
}

Content exchanged for
contact
Before this would be possible, though, it was necessary to conduct indepth persona research and really understand the prospects, leads and customers. Only by gathering as much information as possible regarding decision makers, industries and pain points (to name but a few) would it be possible to create a comprehensive strategy.

\section{Personas}

In order to speak to decision makers with a level of empathy and also expertise, it was vitally important to dig deeper than just the standard demographic information. This research was carried out in a number of ways, including conducting telephone interviews and online surveys with prospects and existing customers within the target industries. It was also necessary to ask salespeople about their experiences with customers to see what the biggest pain points and objections may have been during this stage of the buying process. Once all of the data was gathered, it was analyzed and the patterns and themes for each decision maker highlighted.

The outcome of the research was persona documents that clearly defined the target audience and decision makers, their pain points, typical solutions, common objections and much more. The target audience was identified as owners and managers of small- and medium-sized enterprise care homes and hotels, most of whom were time-poor, dealing with tight budgets and ultimately trying to keep their occupancy rates as high as possible.

\section{Value propositions}

Having completed the persona stage of the process, it was then necessary to create value propositions for the decision makers and influencers within each business type. For the care home industry, we found the key issues that managers and owners experienced were marketing the business, growing the business, saving costs, building and maintaining reputation, and attracting and retaining good staff. This was all in addition to their desire to provide their service users with the best possible care and attention.

In the hotel industry, the pain points were more expected and came in the form of keeping the hotel busy outside peak times, cost-effective local marketing, attracting and retaining good staff, and saving costs. Overall customer experience was also a big consideration for this target audience.

Now that we had this information to hand, it was much easier to plan and strategize the complete marketing campaign and the use of content. By using this information as a base, it was possible to determine the channels and messaging that would engage them most, show thought leadership and also help to build a relationship with the decision makers.

\section{Content distribution and follow-up}

The key objective of a content marketing strategy is to ensure that prospects exchange their contact details for the latest piece of content. 


\section{Easy-to-digest email formats}

\section{Personal and local email}

\section{Qualifying leads by telemarketing}

\section{Content delivers sales}

It was therefore important that once the Miele Professional content had been created, it was hosted (and gated) on a landing page that included a contact form. From this point on, the landing page URL (unique reference location) could be shared via multiple channels, but ultimately drove the prospects to the same destination - and drove conversion into a lead.

As with all integrated marketing campaigns, email was the driving force of the communication channels. Lead generation emails were sent to segmented groups within the database and used relevant messaging to engage the reader. The emails included links to the content landing pages and also provided supporting text to build intrigue and demand. To ensure the content was sensitive to the reader's lack of time, the formats chosen had a conversational tone and did not take a great deal of time to digest. E-books and infographics were popular formats, but we also relied on tip sheets.

Once a prospect had downloaded a piece of content and converted to lead status, they would then be sent a follow-up email. This email was sent in plain-text format to suggest a more personal and one-to-one approach. Importantly, the email was written as if it had been sent directly from the local Miele Professional dealer in the lead's area. This meant that the lead already knew the name of the local dealer and would be more familiar with them further down the sales process.

Having followed up with the lead via email, inside sales (telemarketing) would then be utilized. Telemarketers would call those leads who had downloaded content and attempt to pre-qualify them. Through open questioning and friendly conversation, the telemarketer would look to establish more information about the lead's pain points, current solution, objections to changing suppliers and more. If the lead was sales-ready, the telemarketer would suggest and book an appointment between the lead and their local Miele Professional dealer. If the lead was not sales-ready, they would continue to be nurtured via email, relevant content and telephone calls.

\section{Results}

The results from the Miele Professional multi-channel campaign speak for themselves. Not only did the use of content help to generate a targetexceeding ROI for the overall campaign, but it also helped introduce the contact database to a new form of marketing. Having been provided with relevant content, the decision makers now understand its value and the benefits of working with industry experts. This new desire for more indepth information means that 19 per cent of sales revenue for Miele Professional is now delivered from content.

Other results from the campaign include:

- 566 content downloads - 4.3 per cent of the database;

- 276 inbound sales-ready leads driven purely by content;

- 1,206 leads generated from inbound and outbound follow-up (email and telemarketing);

- 23 per cent uplift in general web leads compared with 2013 (785 leads in total); 
- 19 per cent of sales revenue now delivered from content compared with 100 per cent from outbound telemarketing before 2013;

- 202 per cent increase in value per lead when generated from inbound content;

- 321 per cent ROI;

- 2,260 total leads generated across the campaign.

True believers

\section{Testimonial}

At Really B2B, we have always known the value of adding content to an integrated multi-channel marketing campaign. However, some businesses are still unsure of the potential results it can generate. The team at Miele Professional was truly intrigued and believed that we could deliver the results - and having far exceeded its targets, the company's marketers are now strong advocates of the strategy.

'This campaign has truly surpassed our expectations in terms of engagement with our customers and prospects, our perception as a brand and, most importantly, additional leads and revenue. To say that 19 per cent of our overall sales now come from leads driven by content is fantastic - Really B2B told us it would work and it truly did', says Kate Jones, Marketing Manager, Miele Professional. 